\title{
Prognostic role of neutrophil to lymphocyte ratio in lung cancers: a meta-analysis including 7,054 patients
}

This article was published in the following Dove Press journal:

OncoTargets and Therapy

29 September 2015

Number of times this article has been viewed

\author{
Qing-Tao Zhao' \\ Yong Yang ${ }^{2}$ \\ Shun $\mathrm{Xu}^{3}$ \\ Xiao-Peng Zhang' \\ Hui-En Wang' \\ Hua Zhang' \\ Zhi-Kang Wang' \\ Zheng Yuan' \\ Guo-Chen Duan' \\ 'Department of Thoracic Surgery, \\ Hebei General Hospital, Shijiazhuang, \\ Hebei, ${ }^{2}$ Department of General \\ Surgery, Sujiatun Central Hospital, \\ ${ }^{3}$ Department of Thoracic Surgery, \\ The First Affiliated Hospital, China \\ Medical University, Shenyang, Liaoning, \\ People's Republic of China
}

Correspondence: Guo-Chen Duan Department of Thoracic Surgery, Hebei General Hospital, 348, West He-Ping Road, Shijiazhuang 05005I, Hebei

Province, People's Republic of China

Tel +863 II 85988756

Fax +86 3II 8598876 I

Email hbghospital@I63.com
Background: Neutrophil to lymphocyte ratio (NLR) has recently been reported to be a poor prognostic indicator in lung cancer. However, the prognostic value of the NLR in patients with lung cancer still remains controversial. We performed a meta-analysis to evaluate the prognostic value of NLR in patients with lung cancer.

Methods: We performed a comprehensive literature search in PubMed, Ovid, the Cochrane Library, and Web of Science databases in May 2015. Studies were assessed for quality using the Newcastle-Ottawa Scale.

Results: Twenty-two studies with a total of 7,054 patients were included in this meta-analysis. The meta-analysis was performed to generate combined hazard ratios (HRs) for overall survival (OS) and progression-free survival (PFS). Our analysis results indicated that high NLR predicted poorer OS (HR, 1.51; 95\% confidence interval [CI], 1.33-1.71; $P<0.001)$ and PFS (HR, 1.33; $95 \%$ CI, 1.07-1.67; $P=0.012$ ) in patients with lung cancer. High NLR was also associated with poor OS in lung cancer treated by surgical resection (HR, 1.59; 95\% CI, 1.26-1.99; $P<0.001$ ) and chemotherapy (HR, 1.15; 95\% CI, 1.08-1.22; $P<0.001)$. In addition, NLR cut-off value $=5$ (HR, 1.57; 95\% CI, 1.16-2.12; $P=0.003)$ and NLR cut-off value $<5$ (HR, $1.47 ; 95 \% \mathrm{CI}$, 1.28-1.69; $P<0.001)$.

Conclusion: This meta-analysis result suggested that NLR should have significant predictive ability for estimating OS and PFS in patients with lung cancer and may be as a significant biomarker in the prognosis of lung cancer.

Keywords: NLR, lung cancer, prognosis, meta-analysis

\section{Introduction}

As the second leading cancer type for the estimated new cancer cases, lung cancer represents the major cause of cancer death in both females and males. ${ }^{1}$ Despite research on the diagnosis of lung cancer and the use of increasingly advanced technology in its treatment, the prognosis of lung cancer is still poor. Thus, there is an urgent need for development of prognostic serum biomarkers for the prognosis of lung cancer, which would help clinicians to adopt preventive and personalized medicine for patients with lung cancer.

In recent years, accumulating evidence shown that increased systemic inflammation is associated with poor overall survival (OS) in numerous cancers. ${ }^{2-5}$ Inflammation is a crucial component of tumor microenvironment. ${ }^{5}$ Inflammatory cells in the tumor microenvironment have important effects on tumor development, and markers of systemic inflammation may provide significant information for prognostication. ${ }^{6,7}$ Neutrophil to lymphocyte ratio (NLR), calculated as a simple ratio between neutrophil and lymphocyte 
counts, an index of systemic inflammation, has been related to poor survival for a variety of malignant tumors. ${ }^{8-12}$

Several meta-analyses have showed that NLR has been linked to tumor progression and clinical outcome in many cancers besides lung cancer. ${ }^{13-15}$ Nevertheless, conflicting results have emerged regarding the use of NLR to predict disease progression-free survival (PFS) and OS in lung cancer. ${ }^{16,17}$ Therefore, it is necessary to perform a systemic review and meta-analysis to comprehensively and systematically evaluate the prognostic value of NLR in lung cancer. This study sought to assess and explore the prognostics of NLR for OS and PFS in patients with lung cancer by pooling outcomes from the available data.

\section{Methods}

\section{Search strategy}

We performed a comprehensive literature search of articles through the following databases without date limitation: PubMed, Ovid, the Cochrane Library, and Web of Science databases. The search was updated to May 2015. The main search terms included (NLR or neutrophil to lymphocyte ratio or neutrophil lymphocyte ratio or neutrophil-to-lymphocyte ratio) and (lung cancer or lung carcinoma or NSCLC or SCLC). A manual search of reference lists and potential related articles was also performed.

\section{Data extraction}

All candidate studies were evaluated and extracted by two independent investigators (Qing-Tao Zhao and Yong Yang). The articles, which could not excluded based on title and abstract, were retrieved for full-text review. If disagreement occurred, two investigators discussed and arrived at consensus with the third investigator (Shun $\mathrm{Xu}$ ).

\section{Inclusion criteria}

Studies were included in this meta-analysis if they met the following criteria: 1) Patients with lung cancer in the studies were confirmed by pathological examination, 2) all evaluation indicators were derived from NLR in serum, 3) correlation of NLR with OS and/or PFS of patients with lung cancer was reported, and 4) articles that were not directly recording hazard ratios (HRs) and 95\% confidence interval (CI) were allowed if we could rebuild them by $P$-values and other data reported. ${ }^{18}$

\section{Exclusion criteria}

We excluded articles with any of the following characteristics: 1) abstracts, letters, reviews, expert opinions, case reports, or nonclinical studies; 2) no access to the studies with sufficient data for estimating HR and 95\% CI; 3) studies had duplicate or overlapping data; and 4) studies were not written in English.

\section{Data extraction and quality assessment}

The following items were recorded: first author's name, year of publication, country, total number of cases and sex, follow-ups, stage, cut-off value, cancer type, and HRs with 95\% CIs. The Newcastle-Ottawa Scale (NOS) was used to assess each of the included studies' quality by two independent investigators (Qing-Tao Zhao and Yong Yang). ${ }^{19}$ The NOS consists of three parts: selection (four points), comparability (two points), and outcome assessment (three points). Studies labeled with six or more points were considered to be of high quality.

\section{Statistical analysis}

HR and 95\% CI were procured or estimated from each study according to the methods by Parmar et al. ${ }^{18}$ A HR $>1$ indicated a worse prognosis in patients with lung cancer with high expression of NLR. For each meta-analysis, the Cochrane's $Q$ statistic was undertaken to assess the heterogeneity of the included trials. $I^{2}<50 \%$ represented acceptable no remarkable interstudy heterogeneity, and the fixed-effects (Mantel-Haenszel method) model was applied. Otherwise, the random-effects (DerSimonian-Laird method) model was used. Subgroup analysis and meta-regression analyses were conducted to explore and explain the diversity (heterogeneity) among the results of different studies. All $P$-values were two-sided, and $P<0.05$ was considered statistically significant. Publication bias was assessed by Begg's rank correlation test and Egger's regression asymmetry test. ${ }^{20}$ Trim and fill method was used to assess potential asymmetry in the funnel plot. $^{21}$ Statistical analyses were performed using STATA statistical software version 12.0 (StataCorp LP, College Station, TX, USA).

\section{Results \\ Study characteristics}

The flow chart of the study selection for the meta-analysis is shown in Figure 1. Twenty-two studies with a total of 7,054 patients ${ }^{16,17,22-41}$ were retrieved according to the inclusion and exclusion criteria after careful reading and selection. Of 22 articles, 21 articles investigated the prognostic role of NLR for OS and nine for PFS. Nine studies were from Western countries, including three studies from the US, two studies from the UK, one study from Italy, Spain, Belgium, 


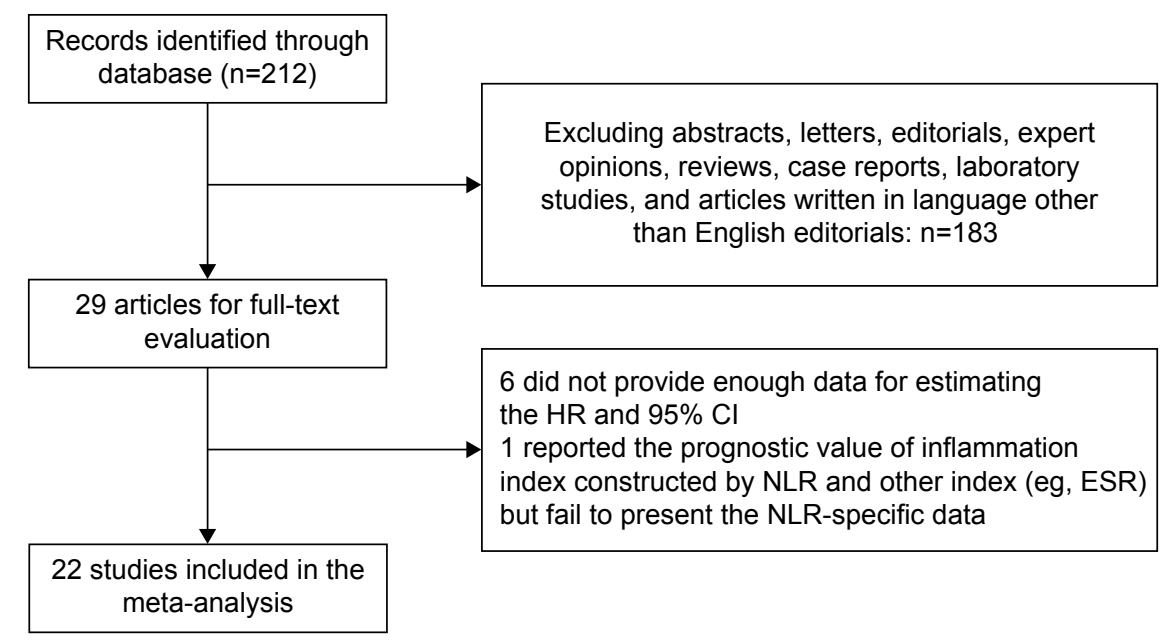

Figure I Flow chart of the included studies.

Abbreviations: $\mathrm{HR}$, hazard ratio; $\mathrm{Cl}$, confidence interval; $\mathrm{NLR}$, neutrophil to lymphocyte ratio; ESR, erythrocyte sedimentation rate.

and Canada. Thirteen studies were from Eastern countries, including five from People's Republic of China, four from Turkey, three from Korea, and one from Japan. All of the studies were retrospective cohort studies. All were reported within the past 5 years, and 82\% were reported in 2013-2015. The characteristics of the included studies were summarized in Table 1.

\section{NLR and OS in lung cancer}

Twenty-one studies evaluated OS for NLR. Though with significant heterogeneity $\left(I^{2}=81.8 \%, P<0.001\right)$, therefore, a random-effects model was applied. The pooled HR of 1.51 (95\% CI, 1.33-1.71; $P<0.001$; Figure 2) showed that patients with elevated NLR were expected to have shorter OS after the treatment.

\section{NLR and PFS in lung cancer}

Nine studies evaluated PFS for NLR. Meta-analysis using the random-effects model demonstrated that high NLR was significantly associated with shorter PFS (HR, $1.33 ; 95 \% \mathrm{CI}$, $1.07-1.67 ; P=0.012$; Figure 3$)$ with heterogeneity $\left(I^{2}=80.5 \%\right.$, $P<0.001)$.

\section{Subgroup analyses}

We further explored potential causes of the heterogeneity in the meta-analysis. Regarding OS, subgroup analysis was performed by the study therapeutic (surgical and chemotherapy), region (eastern and western), NLR cut-off value ( 5 and $<5$ ), type (non-small-cell lung cancer [NSCLC], small-cell lung cancer [SCLC], and NSCLC/SCLC), stage (advanced: III/IV and stage I to stage IV: I/II/III/IV). Regarding PFS, subgroup analyses were also performed based on the treatment; NLR cut-off value and region are shown in Table 2. The pooled results were similar to those for OS. Majority of the subgroup analysis did not alter the prognostic role of NLR in OS/PFS substantially (Table 2).

\section{Publication bias}

Begg's funnel plot and Egger's test linear regression test were presented for the visual assessment of overt publication bias for the included cohorts in NLR. OS and PFS/disease-free survival (DFS) publication bias was not obvious, publication bias was detected for OS $(\operatorname{Pr}>|z|=0.928$ for Begg's test and $P>|t|=0.981$ for Egger's test $)$ and PFS/DFS $(P r>|z|=0.64$ for Begg's test and $P>|t|=0.994$ for Egger's test).

\section{Discussion}

Inflammation plays an important role in tumor initiation and progression. ${ }^{4,42}$ The exact mechanism between inflammation and tumor in these patients with cancer was still undefined. Inflammation-related enhanced neutrophil response and/ or suppression of lymphocyte leading to a high NLR participates in communication between the microenvironment and tumor cells. ${ }^{6,7,43}$ The high NLR potentially balances the functions of neutrophils and lymphocyte, making it a valuable prognostic role in gastric, hepatocellular, colorectal cancers, and so on. ${ }^{9,10,12,44}$ The mechanisms underlying the complex interplay between high NLR and poor outcome of numerous patients with cancers are poorly understood. ${ }^{8,44}$ One reason of the prognostic impact of NLR may be an association of elevated levels of NLR with inflammation. Neutrophil restrain the immune system by suppressing the 


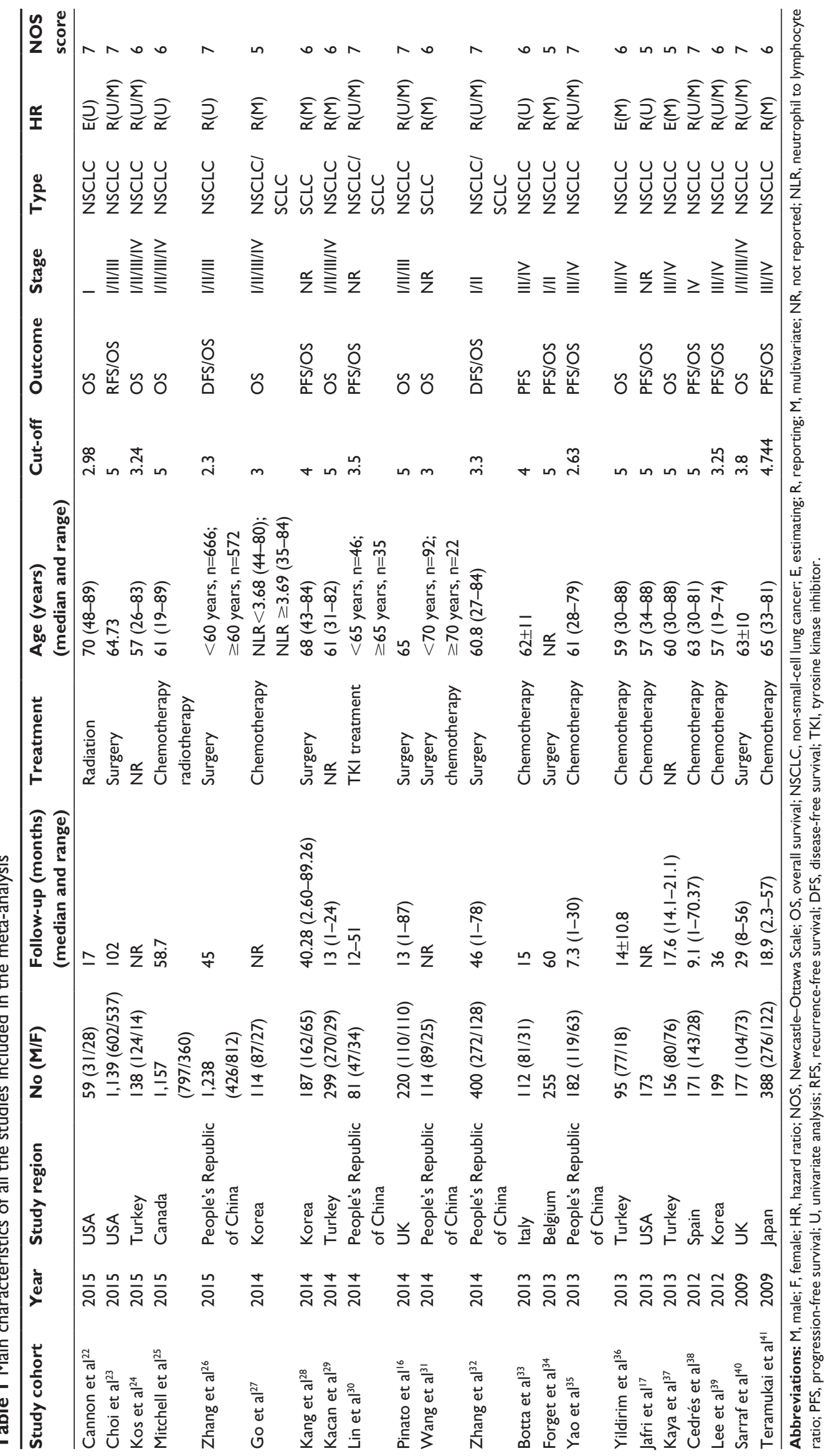




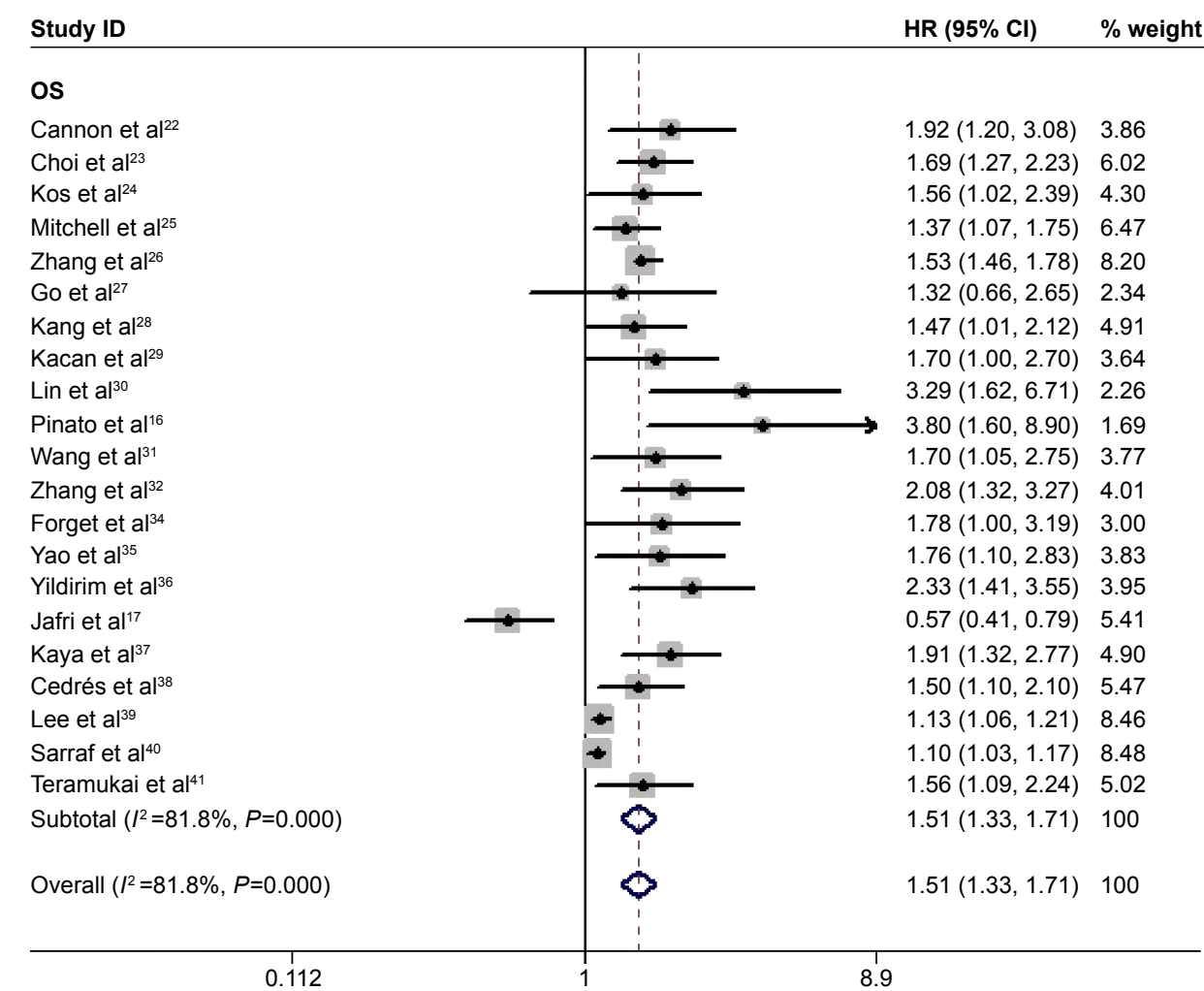

Figure 2 Meta-analysis of the association between NLR and OS of lung cancer. Results are presented as individual and pooled hazard ratio (HR), and $95 \%$ confidence interval $(\mathrm{Cl})$.

Note: Weights are from random-effects analysis.

Abbreviations: NLR, neutrophil to lymphocyte ratio; OS, overall survival.



Figure 3 Meta-analysis of the association between NLR and PFS of lung cancer. Results are presented as individual and pooled hazard ratio (HR), and 95\% confidence interval $(\mathrm{Cl})$.

Note: Weights are from random-effects analysis.

Abbreviations: NLR, neutrophil to lymphocyte ratio; PFS, progression-free survival. 
Table 2 Summary of the meta-analysis results

\begin{tabular}{|c|c|c|c|c|c|c|c|c|}
\hline \multirow[t]{2}{*}{ Analysis } & \multirow[t]{2}{*}{$\mathbf{N}$} & \multirow[t]{2}{*}{ References } & \multicolumn{2}{|c|}{ Random-effects model } & \multicolumn{2}{|l|}{ Fixed-effects model } & \multicolumn{2}{|c|}{ Heterogeneity } \\
\hline & & & HR (95\% CI) & $P$ & HR (95\% Cl) & $P$ & $I^{2}(\%)$ & $P h$ \\
\hline Overall survival (OS) & 21 & $|6| 7,,22-32,34-4 \mid$ & $1.506(1.330,1.706)$ & 0 & $1.229(1.182,1.276)$ & 0 & 81.8 & 0 \\
\hline \multicolumn{9}{|l|}{ Subgroup I } \\
\hline Surgery & 7 & $16,23,26,28,32,34,40$ & $1.587(1.264,1.992)$ & 0 & $1.245(1.182,1.311)$ & 0 & 87.7 & 0 \\
\hline Chemotherapy & 7 & $|7,27,33,35,36,38,4|$ & $1.305(0.983,1.733)$ & 0 & $1.148(1.080,1.221)$ & 0 & 82.5 & 0.066 \\
\hline \multicolumn{9}{|l|}{ Subgroup 2} \\
\hline Eastern countries & 13 & $24,26-32,35-37,39,41$ & $1.638(1.390,1.931)$ & 0 & $1.302(1.236,1.370)$ & 0 & 77.5 & 0 \\
\hline Western countries & 8 & $16,17,22,23,25,34,38,40$ & $1.380(1.067,1.784)$ & 0.014 & $1.143(1.079,1.210)$ & 0 & 84.6 & 0 \\
\hline \multicolumn{9}{|l|}{ Subgroup 3} \\
\hline Cut-off value $=5$ & 9 & $16,17,23,25,29,34,36-38$ & $1.570(1.164,2.116)$ & 0.003 & $1.434(1.270,1.618)$ & 0 & 81.70 & 0.405 \\
\hline Cut-off value $<5$ & 12 & $22,24,26-28,30-32,35,39-4 \mid$ & $1.472(1.280,1.693)$ & 0 & $1.208(1.160,1.257)$ & 0 & 81.4 & 0 \\
\hline \multicolumn{9}{|l|}{ Subgroup 4} \\
\hline NSCLC & 16 & $|6| 7,,22-26,29,34-4 \mid$ & $1.447(1.266,1.654)$ & 0 & $1.215(1.169,1.263)$ & 0 & 84.1 & 0 \\
\hline SCLC & 2 & 28,31 & $1.549(1.156,2.077)$ & 0.003 & $1.549(1.156,2.077)$ & 0.003 & 0.00 & 0.626 \\
\hline NSCLC/SCLC & 3 & $27,30,32$ & $2.073(1.329,3.234)$ & 0.001 & $2.070(1.480,2.895)$ & 0 & 38 & 0.199 \\
\hline \multicolumn{9}{|l|}{ Subgroup 5} \\
\hline I/II/III/IV & 5 & $24,25,27,29,40$ & $1.295(1.073,1.563)$ & 0.007 & I.I3। (I.065, I.202) & 0 & 50.3 & 0.090 \\
\hline Advanced: III/IV & 6 & $33,35-37,39,41$ & $\mathrm{I} .583(\mathrm{I} .222,2.05 \mathrm{I})$ & 0.001 & $1.193(1.121,1.269)$ & 0.001 & 77.7 & 0 \\
\hline \multicolumn{9}{|l|}{ Subgroup 6} \\
\hline Sample size $\geq 200$ & 8 & $|6,23,25,26,29,32,34,4|$ & $1.576(\mathrm{I} .433, \mathrm{I} .733)$ & 0 & 1.565 (I.44I, I.699) & 0 & 5.9 & 0.385 \\
\hline Sample size $<200$ & 13 & $17,22,24,27,28,30,31,35-40$ & $1.395(1.202,1.619)$ & 0 & $1.149(1.101,1.200)$ & 0 & 79.9 & 0 \\
\hline \multicolumn{9}{|l|}{ Subgroup 7} \\
\hline Univariate analysis & 13 & $16,17,22-26,30,32,35,38-40$ & $1.420(1.242,1.623)$ & 0 & $1.200(1.160,1.24 I)$ & 0 & 88.2 & 0.001 \\
\hline Multivariate analysis & 17 & $|6,23,24,27-32,34-4|$ & $1.58 \mathrm{I}(1.386,1.803)$ & 0 & $1.189(1.139,1.240)$ & 0 & 74.9 & 0 \\
\hline Progression-free survival (PFS) & 9 & $|7,28,30,33-35,38,39,4|$ & $1.334(1.066,1.670)$ & 0.012 & $1.230(1.161,1.304)$ & 0 & 80.5 & 0 \\
\hline \multicolumn{9}{|l|}{ Subgroup I } \\
\hline Surgery & 2 & 28,34 & $1.462(1.138,1.877)$ & 0.003 & $1.462(1.138,1.877)$ & 0.003 & 0.00 & 0.949 \\
\hline Chemotherapy & 6 & $|7,33,35,38,39,4|$ & I.I73 (0.90I, I.527) & 0.235 & $1.207(1.137,1.282)$ & 0 & 82.0 & 0 \\
\hline \multicolumn{9}{|l|}{ Subgroup 2} \\
\hline Eastern countries & 5 & $28,30,35,39,4 I$ & $1.598(1.216,2.099)$ & 0.001 & $1.266(1.190,1.347)$ & 0 & 73.3 & 0.005 \\
\hline Western countries & 4 & $17,33,34,38$ & $1.065(0.683,1.660)$ & 0.782 & $0.991(0.836,1.175)$ & 0.919 & 84.30 & 0 \\
\hline \multicolumn{9}{|l|}{ Subgroup 3} \\
\hline Cut-off value $=5$ & 3 & $17,34,38$ & $0.94 \mathrm{I}(0.575, \mathrm{I} .54 \mathrm{I})$ & 0.809 & $0.930(0.776, \mathrm{I} .1 \mathrm{I} 3)$ & 0.429 & 86.30 & 0.001 \\
\hline Cut-off value $<5$ & 6 & $28,30,33,35,39,41$ & $1.596(1.250,2.037)$ & 0 & $1.27 \mathrm{I}(\mathrm{I} .195, \mathrm{I} .35 \mathrm{I})$ & 0 & 68.9 & 0.007 \\
\hline \multicolumn{9}{|l|}{ Subgroup 4} \\
\hline Univariate analysis & 6 & $17,30,33,35,38,39$ & $1.36 \mathrm{I}(0.956,1.938)$ & 0.087 & $1.227(1.159,1.299)$ & 0 & 88.5 & 0 \\
\hline Multivariate analysis & 6 & $28,30,34,35,39,41$ & $1.547(1.237,1.935)$ & 0 & $1.27 \mathrm{I}(\mathrm{I} .196,1.35 \mathrm{I})$ & 0 & 67.9 & 0.008 \\
\hline NSCLC & 7 & $|7,33-35,38,39,4|$ & $1.205(0.958,1.517)$ & 0.112 & $1.213(1.143,1.287)$ & 0 & 79.2 & 0 \\
\hline
\end{tabular}

Note: Meta-regression analysis was applied only if the pooled cohorts exceeded 10.

Abbreviations: N, number of studies; HR, hazard ratio; Cl, confidence interval, Ph, P-value of Q-test for heterogeneity test; NSCLC, non-small-cell lung cancer.

cytolytic activity of activated T-cells, lymphocytes, and natural killer cells., ${ }^{2,45}$ However, the significance of lymphocytes has been highlighted in some studies in which increasing infiltration of tumors with lymphocytes may play a key role in cytotoxic treatment and prognosis in patients with cancer. ${ }^{4,46}$

NLR was frequently used as an inflammatory marker, while its prognostic role in lung cancer was revealed just during the recent years. The present meta-analysis demonstrated that the elevated level of NLR is associated with the poor survival of lung cancer. A prognostic role was demonstrated for both OS and PFS of patients with lung cancer. ${ }^{47}$
Similar to our study, two recent meta-analyses confirmed the prognostic value of the NLR in colorectal cancer and hepatocellular carcinoma. ${ }^{13,14}$ Though with heterogeneity, subgroup estimation in the present study showed that high NLR was an effective prognostic factor for poor OS of patients with lung cancer who received various types of treatment including surgical resection and chemotherapy. There was also a significant association between NLR and therapeutic and cut-off value NLR $=5 /<5$. Taking all these into consideration, NLR is a promising prognostic inflammation marker helpful for the clinical decision-making process regarding lung cancer treatment and outcomes. 
Limitations of this meta-analysis deserve comment. First, the majority of the enrolled studies were retrospective, which was more susceptible to some biases. Second, heterogeneity is a potential problem that may affect the interpretation of the results of all meta-analyses. The presence of heterogeneity may result from many other factors, including age distribution, sex, NLR cut-off value, and so on. Third, NLR was not included in the multivariate analysis because it failed to gain statistical significance in the univariate analysis. The corresponding HR and 95\% CI could only be retrieved from univariate analysis. The accuracy of the pooled estimates may thus be impaired. Fourth, publication bias inevitably hides in meta-analysis since positive results were more likely to be published than negative ones. A tendency for journals to only publish positive results leads to a larger magnitude of an association in pooled analysis than the actual value.

In conclusion, this meta-analysis demonstrated that the high NLR is associated with worse prognosis for patients with lung cancer. NLR seems to be a convenient, repeated, inexpensive, widely available, and reliable to predict the survival and treatment response of patients with lung cancer. In future, more research with better design to test this hypothesis is necessary.

\section{Disclosure}

The authors declare that they have no conflicts of interest in this work.

\section{References}

1. Siegel RL, Miller KD, Jemal A. Cancer statistics, 2015. CA Cancer J Clin. 2015;65(1):5-29.

2. Coussens LM, Werb Z. Inflammation and cancer. Nature. 2002; 420(6917):860-867.

3. Balkwill F, Mantovani A. Inflammation and cancer: back to Virchow? Lancet. 2001;357(9255):539-545.

4. Grange JM, Krone B, Mastrangelo G. Infection, inflammation and cancer. Int J Cancer. 2011;128(9):2240-2241.

5. Moore MM, Chua W, Charles KA, Clarke SJ. Inflammation and cancer: causes and consequences. Clin Pharmacol Ther. 2010;87(4):504-508.

6. de Visser KE, Coussens LM. The inflammatory tumor microenvironment and its impact on cancer development. Contrib Microbiol.2006;13: $118-137$

7. Joyce JA. Therapeutic targeting of the tumor microenvironment. Cancer Cell. 2005;7(6):513-520.

8. Keizman D, Ish-Shalom M, Huang P, et al. The association of pretreatment neutrophil to lymphocyte ratio with response rate, progression free survival and overall survival of patients treated with sunitinib for metastatic renal cell carcinoma. Eur J Cancer. 2012;48(2): 202-208.

9. Guthrie GJ, Roxburgh CS, Farhan-Alanie OM, Horgan PG, McMillan DC. Comparison of the prognostic value of longitudinal measurements of systemic inflammation in patients undergoing curative resection of colorectal cancer. Br J Cancer. 2013;109(1):24-28.

10. Oh BS, Jang JW, Kwon JH, et al. Prognostic value of C-reactive protein and neutrophil-to-lymphocyte ratio in patients with hepatocellular carcinoma. BMC Cancer. 2013;13:78.
11. Sharaiha RZ, Halazun KJ, Mirza F, et al. Elevated preoperative neutrophil:lymphocyte ratio as a predictor of postoperative disease recurrence in esophageal cancer. Ann Surg Oncol. 2011;18(12):3362-3369.

12. Yamanaka T, Matsumoto S, Teramukai S, Ishiwata R, Nagai Y, Fukushima M. The baseline ratio of neutrophils to lymphocytes is associated with patient prognosis in advanced gastric cancer. Oncology. 2007; 73(3-4):215-220.

13. Li MX, Liu XM, Zhang XF, et al. Prognostic role of neutrophil-tolymphocyte ratio in colorectal cancer: a systematic review and metaanalysis. Int J Cancer. 2014;134(10):2403-2413.

14. Xiao WK, Chen D, Li SQ, Fu SJ, Peng BG, Liang LJ. Prognostic significance of neutrophil-lymphocyte ratio in hepatocellular carcinoma: a meta-analysis. BMC Cancer. 2014;14:117.

15. Wei Y, Jiang YZ, Qian WH. Prognostic role of NLR in urinary cancers: a meta-analysis. PLoS One. 2014;9(3):e92079.

16. Pinato DJ, Shiner RJ, Seckl MJ, Stebbing J, Sharma R, Mauri FA. Prognostic performance of inflammation-based prognostic indices in primary operable non-small cell lung cancer. Br J Cancer. 2014;110(8):1930-1935.

17. Jafri SH, Shi R, Mills G. Advance lung cancer inflammation index (ALI) at diagnosis is a prognostic marker in patients with metastatic non-small cell lung cancer (NSCLC): a retrospective review. BMC Cancer. 2013;13:158.

18. Parmar MK, Torri V, Stewart L. Extracting summary statistics to perform meta-analyses of the published literature for survival endpoints. Stat Med. 1998;17(24):2815-2834.

19. Wells GA, Shea B, O'Connell D, et al. The Newcastle-Ottawa Scale (NOS) for Assessing the Quality of Nonrandomised Studies in Meta-Analyses. Available from: http://www.ohri.ca/programs/ clinical_epidemiology/oxford.asp. Accessed July 10, 2014.

20. Egger M, Davey SG, Schneider M, Minder C. Bias in meta-analysis detected by a simple, graphical test. BMJ. 1997;315(7109):629-634.

21. Duval S, Tweedie R. Trim and fill: a simple funnel-plot-based method of testing and adjusting for publication bias in meta-analysis. Biometrics. 2000;56(2):455-463.

22. Cannon NA, Meyer J, Iyengar P, et al. Neutrophil-lymphocyte and platelet-lymphocyte ratios as prognostic factors after stereotactic radiation therapy for early-stage non-small-cell lung cancer. J Thorac Oncol. 2015; 10(2):280-285.

23. Choi JE, Villarreal J, Lasala J, et al. Perioperative neutrophil:lymphocyte ratio and postoperative NSAID use as predictors of survival after lung cancer surgery: a retrospective study. Cancer Med. 2015;4(6):825-833.

24. Kos FT, Hocazade C, Kos M, et al. Assessment of prognostic value of "neutrophil to lymphocyte ratio" and "prognostic nutritional index" as a sytemic inflammatory marker in non-small cell lung cancer. Asian Pac J Cancer Prev. 2015;16(9):3997-4002.

25. Mitchell P, Thatcher N, Socinski MA, et al. Tecemotide in unresectable stage III non-small-cell lung cancer in the phase III START study: updated overall survival and biomarker analyses. Ann Oncol. 2015;26(6):1134-1142.

26. Zhang H, Zhang L, Zhu K, et al. Prognostic significance of combination of preoperative platelet count and neutrophil-lymphocyte ratio (COP-NLR) in patients with non-small cell lung cancer: based on a large cohort study. PLoS One. 2015;10(5):e126496.

27. Go SI, Lee A, Lee US, et al. Clinical significance of the neutrophillymphocyte ratio in venous thromboembolism patients with lung cancer. Lung Cancer. 2014;84(1):79-85.

28. Kang MH, Go SI, Song HN, et al. The prognostic impact of the neutrophil-to-lymphocyte ratio in patients with small-cell lung cancer. Br J Cancer. 2014;111(3):452-460.

29. Kacan T, Babacan NA, Seker M, et al. Could the neutrophil to lymphocyte ratio be a poor prognostic factor for non small cell lung cancers? Asian Pac J Cancer Prev. 2014;15(5):2089-2094.

30. Lin GN, Peng JW, Liu PP, Liu DY, Xiao JJ, Chen XQ. Elevated neutrophil-to-lymphocyte ratio predicts poor outcome in patients with advanced non-small-cell lung cancer receiving first-line gefitinib or erlotinib treatment. Asia Pac J Clin Oncol. Epub 2014 Oct 31. 
31. Wang X, Jiang R, Li K. Prognostic significance of pretreatment laboratory parameters in combined small-cell lung cancer. Cell Biochem Biophys. 2014;69(3):633-640.

32. Zhang T, Jiang Y, Qu X, Shen H, Liu Q, Du J. Evaluation of preoperative hematologic markers as prognostic factors and establishment of novel risk stratification in resected pN0 non-small-cell lung cancer. PLoS One. 2014;9(10):e111494.

33. Botta C, Barbieri V, Ciliberto D, et al. Systemic inflammatory status at baseline predicts bevacizumab benefit in advanced non-small cell lung cancer patients. Cancer Biol Ther. 2013;14(6):469-475.

34. Forget P, Machiels JP, Coulie PG, et al. Neutrophil:lymphocyte ratio and intraoperative use of ketorolac or diclofenac are prognostic factors in different cohorts of patients undergoing breast, lung, and kidney cancer surgery. Ann Surg Oncol. 2013;20(suppl 3):S650-S660.

35. Yao Y, Yuan D, Liu H, Gu X, Song Y. Pretreatment neutrophil to lymphocyte ratio is associated with response to therapy and prognosis of advanced non-small cell lung cancer patients treated with first-line platinum-based chemotherapy. Cancer Immunol Immunother. 2013;62(3):471-479.

36. Yildirim M, Yildiz M, Duman E, Goktas S, Kaya V. Prognostic importance of the nutritional status and systemic inflammatory response in non-small cell lung cancer. J BUON. 2013;18(3):728-732.

37. Kaya V, Yildirim M, Demirpence O, Yildiz M, Yalcin AY. Prognostic significance of basic laboratory methods in non- small-cell-lung cancer. Asian Pac J Cancer Prev. 2013;14(9):5473-5476.

38. Cedrés S, Torrejon D, Martínez A, et al. Neutrophil to lymphocyte ratio (NLR) as an indicator of poor prognosis in stage IV non-small cell lung cancer. Clin Transl Oncol. 2012;14(11):864-869.

39. Lee Y, Kim SH, Han JY, Kim HT, Yun T, Lee JS. Early neutrophil-tolymphocyte ratio reduction as a surrogate marker of prognosis in never smokers with advanced lung adenocarcinoma receiving gefitinib or standard chemotherapy as first-line therapy. J Cancer Res Clin Oncol. 2012; 138(12):2009-2016.
40. Sarraf KM, Belcher E, Raevsky E, Nicholson AG, Goldstraw P, Lim E. Neutrophil/lymphocyte ratio and its association with survival after complete resection in non-small cell lung cancer. J Thorac Cardiovasc Surg. 2009;137(2):425-428.

41. Teramukai S, Kitano T, Kishida Y, et al. Pretreatment neutrophil count as an independent prognostic factor in advanced non-small-cell lung cancer: an analysis of Japan Multinational Trial Organisation LC00-03. Eur J Cancer. 2009;45(11):1950-1958.

42. Proctor MJ, Morrison DS, Talwar D, et al. A comparison of inflammationbased prognostic scores in patients with cancer. A glasgow inflammation outcome study. Eur J Cancer. 2011;47(17):2633-2641.

43. Proctor MJ, McMillan DC, Morrison DS, Fletcher CD, Horgan PG, Clarke SJ. A derived neutrophil to lymphocyte ratio predicts survival in patients with cancer. Br J Cancer. 2012;107(4):695-699.

44. Szkandera J, Gerger A, Liegl-Atzwanger B, et al. The lymphocyte/ monocyte ratio predicts poor clinical outcome and improves the predictive accuracy in patients with soft tissue sarcomas. Int $J$ Cancer. 2014;135(2):362-370.

45. Mantovani A, Allavena P, Sica A, Balkwill F. Cancer-related inflammation. Nature. 2008;454:436-444.

46. Erdman SE, Poutahidis T. Cancer inflammation and regulatory T cells. Int J Cancer. 2010;127(7203):768-779.

47. O'Callaghan DS, O'Donnell D, O'Connell F, O'Byrne KJ. The role of inflammation in the pathogenesis of non-small cell lung cancer. J Thorac Oncol. 2010;5(12):2024-2036.
OncoTargets and Therapy

\section{Publish your work in this journal}

OncoTargets and Therapy is an international, peer-reviewed, open access journal focusing on the pathological basis of all cancers, potential targets for therapy and treatment protocols employed to improve the management of cancer patients. The journal also focuses on the impact of management programs and new therapeutic agents and protocols on

\section{Dovepress}

patient perspectives such as quality of life, adherence and satisfaction The manuscript management system is completely online and includes a very quick and fair peer-review system, which is all easy to use. Visit http://www.dovepress.com/testimonials.php to read real quotes from published authors. 